\title{
Environmental fate of insecticides on the biological matrices as a function of temperature: A pilot study
}

\author{
Poulomi Saha ${ }^{1 *}$, Shailendra Sharma ${ }^{2}$, Suryansh Shukla ${ }^{3}$, P. Sharma ${ }^{4}$ \\ ${ }^{1,2}$ Independent Researchers, ${ }^{3}$ Student, Amity International, Vasundhara, Ghaziabad, Uttar Pradesh ${ }^{4}$ Director, Supreme Testing \\ Lab and Forensic Evidence Protection Technology Pvt Ltd (STEP), Rohini, New Delhi
}

*Corresponding Author:

Email: saha.poulomisaha@gmail.com

\begin{abstract}
Toxicology division of Forensic Science Labs (FSLs) frequently receives samples containing insecticides. Due to pendency of medico legal cases, biological samples are often stored for some time i.e from the time of collection until analysis. The role of temperature and putrefaction that may inevitably interfere with analysis results which is often ignored in such cases. In the present study, an attempt has been made to produce evidences by differentiating Thin Layer Chromatographic (TLC) results of the insecticides- Carbofuran and Carbaryl (1-naphthyl methylcarbamate) as a direct consequence of changes in the preservation methods of samples. Research must be extensively done taking into consideration of the factors like temperature, humidity, duration of time etc. so as to support studies on better preservation methodologies of Forensic samples.
\end{abstract}

Keywords: Insecticides, Carbofuran, Carbaryl, Toxicology, Temperature, Putrefaction, Chromatography.

\section{Introduction}

Insecticides are substances used to kill insects. Insecticides can be classified into two major groups: systemic insecticides which have long term and residual activity and contact insecticides which have no residual activity. Furthermore, insecticides are distinguished into natural insecticides eg. nicotine, pyrethrum and neem extracts, made by plants as defenses against insects; Inorganic insecticides which are metals; Organic insecticides, which are organic chemical compounds, mostly work by contact. Systemic insecticides get distributed systemically throughout the whole plant. When insects feed on the plant, they ingest the insecticide. Contact insecticides are toxic to insects upon direct contact. These can be inorganic insecticides, which are metals and include arsenates, copper and fluorine compounds, which are less commonly used, and the commonly used sulfur. Contact insecticides can be organic insecticides, i.e. organic chemical compounds, synthetically produced, and comprising the largest numbers of pesticides used today. Or they can be natural compounds like pyrethrum, neem oil etc. Contact insecticides usually have no residual activity. Carbamates are contact insecticides. They interfere with the enzymes acetylcholinesterase and

other cholinesterases, disrupting nerve impulses and killing or disabling the insect, have shorter duration of action and are less toxic.

The so-called carbamate insecticides feature the carbamate ester functional group. Included in this group are aldicarb (Temik), carbofuran (Furadan), carbaryl (S evin), ethienocarb, fenobucarb, oxamyl,

and methomyl. These insecticides kill insects by reversibly inactivating the enzyme acetylcholinesterase. While the carbamate acetylcholinesterase inhibitors are commonly referred to as "carbamate insecticides" due to their generally high selectivity for insect acetylcholinesterase enzymes over the mammalian versions, the most potent compounds such as aldicarb and carbofuran are still capable of inhibiting mammalian acetylcholinesterase enzymes at low enough concentrations that they pose a significant risk of poisoning to humans. Carbamate insecticides target human melatonin receptors, along with inhibiting acetylcholinesterase. $^{1}$

The use of insecticides for criminal purposes has not only increased but their analyses complexities have also grown over decades. Insecticides have largely been abused for suicides/ homicides because of their ease of availability in regular use for controlling mosquitoes, cockroaches, bugs, flies etc. Deaths in suspicious circumstances are reported as medico legal death cases and the post mortem samples are forwarded to FSLs for analyses. Forensic Toxicology is a special area of analytical Chemistry that deals with analyses of poisons in samples like blood, viscera, body fluids etc. There are number of factors responsible for affecting the analytical results and therefore, no standardized protocols for the identification of poisons in biological samples can be followed. In this study, efforts have been made to study the putrefaction of biological samples on the analysis of two insecticides- Carbafuran and Carbary. ${ }^{1}$

Death as a reason of poisoning/drug abuse is of enormous medical, legal and social significance. Due to easy availability of poisons and low cost, many people prefer it for the purpose of suicide, as poisons leading peaceful death. Even though the advanced medical treatment and awareness, the poisoning cases are increasing day by day. ${ }^{2}$

Insecticides group which constituted 245 (30.65\%) which was most common cause of poisoning, out of which organophosphorus poisoning was 139 (17.39\%), 
Carbamate $47(5.88 \%)$ and organocholorine was 59 $(7.38 \%)$ cases. Next common poisoning cause was drugs like Diazepam, Alprazolam, Crocin, Iron, were most commonly used. Over the last few decades agricultural pesticides have become a common household item in rural areas of the developing world. Due to their easy availability, pesticides have also become commonly used for intentional self-poisoning. Pesticide poisoning is a significant problem in India. ${ }^{3}$

\section{Materials and Methods}

Table 1: Reagents and Chemicals

\begin{tabular}{|c|c|c|}
\hline S.No. & Chemicals & Source \\
\hline 1 & Chloroform & Merck, Mumbai \\
\hline 2 & Acetic Acid & -do- \\
\hline 3 & Acetonitrile & -do- \\
\hline 4 & Methanol & Glaxo India Ltd., Mumbai \\
\hline 5 & n-Hexane & -do- \\
\hline 6 & Acetone & -do- \\
\hline 7 & Benzene & -do- \\
\hline
\end{tabular}

Insecticides Standards: Carbofuran and Carbaryl (Technical Grade) were prepared in Acetone at concentrations of $0.01,0.05,0.10,0.50$ and $1.00 \mathrm{mg} / \mathrm{ml}$. Study Protocol: To carry out detailed study for obtaining the best solvent system for detection of
Carbafuran and Carbaryl insecticides and to study the environmental fate of insecticides on the biological matrices as a function of temperature.

Sample Size: 10 samples (goat liver) each in preserved and putrefied conditions.

Table 2: Showing the samples taken for the study

2ml Standard soln. of Carbofuran at $1 \mathrm{mg} / \mathrm{ml}$

$2 \mathrm{ml}$ Standard soln. of Carbaryl at $1 \mathrm{mg} / \mathrm{ml}$

\begin{tabular}{|c|c|c|c|}
\hline $\begin{array}{c}\text { Carbafuran (Preserved) } \\
\text { Cf(Pr) }\end{array}$ & $\begin{array}{c}\text { Carbafuran (Putrefied) } \\
\text { Cf(Pt) }\end{array}$ & $\begin{array}{c}\text { Carbaryl (Preserved) } \\
\text { Cr(Pr) }\end{array}$ & $\begin{array}{c}\text { Carbaryl (Putrefied) } \\
\text { Cr(Pt) }\end{array}$ \\
\hline Standard & $\mathrm{Standard}$ & $\mathrm{Standard}$ & Standard \\
\hline $\mathrm{Cf}(\mathrm{Pr}) 1$ & $\mathrm{Cf}(\mathrm{Pt}) 1$ & $\mathrm{Cr}(\mathrm{Pr}) 1$ & $\mathrm{Cr}(\mathrm{Pt}) 1$ \\
\hline $\mathrm{Cf}(\mathrm{Pr}) 2$ & $\mathrm{Cf}(\mathrm{Pt}) 2$ & $\mathrm{Cr}(\operatorname{Pr}) 2$ & $\mathrm{Cr}(\mathrm{Pt}) 2$ \\
\hline $\mathrm{Cf}(\mathrm{Pr}) 3$ & $\mathrm{Cf}(\mathrm{Pt}) 3$ & $\mathrm{Cr}(\mathrm{Pr}) 3$ & $\mathrm{Cr}(\mathrm{Pt}) 3$ \\
\hline $\mathrm{Cf}(\mathrm{Pr}) 4$ & $\mathrm{Cf}(\mathrm{Pt}) 4$ & $\mathrm{Cr}(\mathrm{Pr}) 4$ & $\mathrm{Cr}(\mathrm{Pt}) 4$ \\
\hline $\mathrm{Cf}(\mathrm{Pr}) 5$ & $\mathrm{Cf}(\mathrm{Pt}) 5$ & $\mathrm{Cr}(\mathrm{Pr}) 5$ & $\mathrm{Cr}(\mathrm{Pt}) 5$ \\
\hline $\mathrm{Cf}(\mathrm{Pr}) 6$ & $\mathrm{Cf}(\mathrm{Pt}) 6$ & $\mathrm{Cr}(\mathrm{Pr}) 6$ & $\mathrm{Cr}(\mathrm{Pt}) 6$ \\
\hline $\mathrm{Cf}(\mathrm{Pr}) 7$ & $\mathrm{Cf}(\mathrm{Pt}) 7$ & $\mathrm{Cr}(\mathrm{Pr}) 7$ & $\mathrm{Cr}(\mathrm{Pt}) 7$ \\
\hline $\mathrm{Cf}(\mathrm{Pr}) 8$ & $\mathrm{Cf}(\mathrm{Pt}) 8$ & $\mathrm{Cr}(\mathrm{Pr}) 8$ & $\mathrm{Cr}(\mathrm{Pt}) 8$ \\
\hline $\mathrm{Cf}(\mathrm{Pr}) 9$ & $\mathrm{Cf}(\mathrm{Pt}) 9$ & $\mathrm{Cr}(\mathrm{Pr}) 9$ & $\mathrm{Cr}(\mathrm{Pt}) 9$ \\
\hline $\mathrm{Cf}(\mathrm{Pr}) 10$ & $\mathrm{Cf}(\mathrm{Pt}) 10$ & $\mathrm{Cr}(\mathrm{Pr}) 10$ & $\mathrm{Cr}(\mathrm{Pt}) 10$ \\
\hline
\end{tabular}

Table 3: Showing Different Solvent Systems Used For Carbafuran

\begin{tabular}{|c|l|}
\hline S. No. & Solvent Systems Used \\
\hline 1 & Hexane : Acetone $(9: 1)$ \\
\hline 2 & Hexane : Acetone $(8: 2)$ \\
\hline 3 & Hexane : Acetone $(7: 3)$ \\
\hline 4 & Benzene : Chloroform : Acetone $(6: 3: 1)$ \\
\hline 5 & Hexane : Benzene $:$ Chloroform : Acetic Acid $(6: 2: 2: 5)$ \\
\hline 6 & Benzene : Methanol $(4: 6)$ \\
\hline
\end{tabular}

Table 4: Showing Different solvent systems used for carbaryl

\begin{tabular}{|c|c|}
\hline S. No. & Solvent Systems Used \\
\hline 1 & Hexane : Acetone $(9: 1)$ \\
\hline 2 & Hexane : Benzene $(6: 4)$ \\
\hline 3 & Hexane : Acetone $(7: 3)$ \\
\hline
\end{tabular}




\begin{tabular}{|l|l|}
\hline 4 & Hexane : Acetone $(8: 2)$ \\
\hline 5 & Acetone : Benzene $(7: 3)$ \\
\hline 6 & Acetone : Benzene $(6: 4)$ \\
\hline
\end{tabular}

Parameters of Samples testing: Solvent systems, Temperature, Putrefication.

Extraction and Purification (Sample Preparation): The samples were homogenized and refluxed with $\mathrm{n}$ hexane $(50 \mathrm{ml})$ on a hot water bath for 90 minutes. The contents were cooled, filtered and the residue is extracted twice with $\mathrm{n}$-hexane $(25 \mathrm{ml})$ saturated with

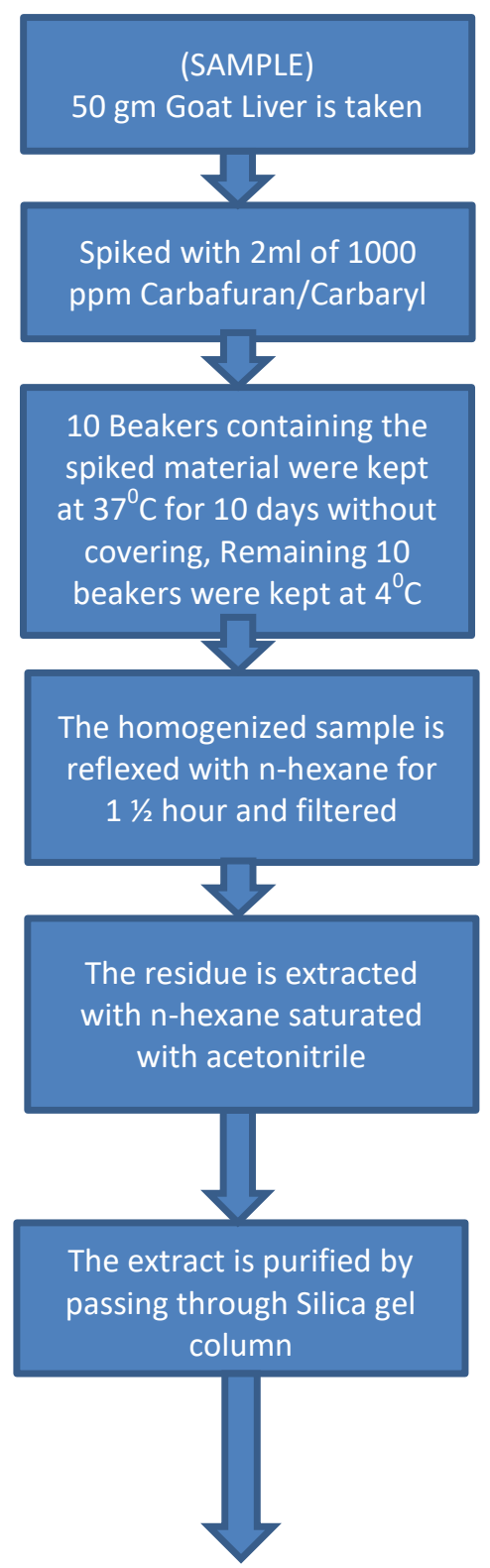

acetonitrile. The extract was dehydrated, purified by passing through Sodium Sulphate and Silica Gel G column and evaporated to dryness on a water bath. The residue was reconstituted in $1 \mathrm{ml}$ of $\mathrm{n}$-hexane and TLC was performed with the extracted and purified sample.

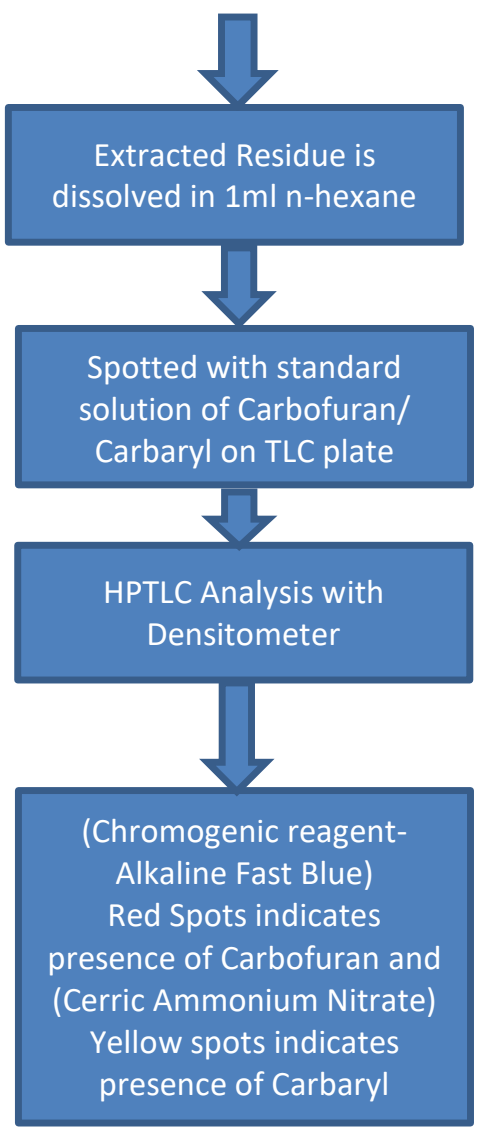

Fig. 1: Showing extraction and detection of Carbamate group of insecticides (Carbofuran and Carbaryl) from Biological tissue (Goat liver) 
Instrumentation: High Performance Thin Layer Chromatography (HPTLC)

HPTLC plates were activated at $110^{\circ} \mathrm{C}$ for $30 \mathrm{mins}$, cooled to room temperature before analysis. Spotting of standard solutions and extracted samples was done by HPTLC sample applicator (Desaga-AS-30, Germany). The plates were placed in developing chamber and different solvent systems (Table $3 \& 4$ ) were tested. After elution of spots, the plates were air dried and scanned by multi wavelength program and lambda max values were noted for specific densitograms of each insecticide on Desaga- Densitometer-CD20, Germany.

\section{Results \& Discussion}

The extraction of insecticides from Biological matrix like viscera is difficult due to interferences from fat, degraded protein, colouring matter etc. Out of the several solvents tried, it was observed that percentage recoveries of insecticides from visceral tissue were maximum for hexane as extracting solvent (85-90\%) at microgram level. The recoveries may further be increased by using solid phase extraction (SPE) technique to detect the insecticides at nanogram level.

Various solvent systems that were used for HPTLC showed that the $\mathrm{Rf}$ values varied with polarity of the solvents used and thus the choice of the solvent for a particular insecticide is very important. It was observed that there was a difference in $\mathrm{RF}$ values of putrefied (Kept at $37^{\circ} \mathrm{C}$ ) and preserved (kept at $4^{\circ} \mathrm{C}$ ) samples in all the three solvent systems tested (Table 5 and 6 ). In case of Carbofuran, the putrefied samples showed higher Rf value as compared to preserved sample.

In case of Carbaryl, the number of spots observed for putrefied samples was more than preserved samples. The possible reason may be the degradation of the insecticide due to high temperature and/or exposure to daylight. These results were also supported by HPTLC densitograms where more than one peak was observed for putrefied sample of RT2. The results of HPTLC also show that below $0.01 \mathrm{mg} / \mathrm{ml}$, neither of the insecticides could be detected at their respective lambda max.

Table 5: Showing Effect Of Different Solvent Systems On The Analysis Of Carbafuran

\begin{tabular}{|c|l|c|c|}
\hline S. No. & Solvent Systems Used & Rf of Standard & Rf of Extracted Sample \\
\hline 1 & Hexane : Acetone $(9: 1)$ & 0.48 & 0.48 \\
\hline 2 & Hexane : Acetone $(8: 2)$ & 0.48 & 0.48 \\
\hline 3 & Hexane : Acetone (7:3) & 0.45 & 0.45 \\
\hline 4 & Benzene : Chloroform : Acetone $(6: 3: 1)$ & 0.40 & 0.40 \\
\hline 5 & Hexane : Benzene : Chloroform : Acetic Acid (6:2:2:5) & 0.35 & 0.35 \\
\hline 6 & Benzene : Methanol (4:6) & 0.58 & 0.58 \\
\hline
\end{tabular}

Table 6: Showing Effect of different solvent systems on the analysis Of Carbaryl

\begin{tabular}{|c|c|c|c|}
\hline S. No. & Solvent Systems Used & Rf of Standard & Rf of Extracted Sample \\
\hline 1 & Hexane : Acetone $(9: 1)$ & 0.41 & 0.41 \\
\hline 2 & Hexane : Benzene $(6: 4)$ & 0.49 & 0.47 \\
\hline 3 & Hexane : Acetone $(7: 3)$ & 0.45 & 0.45 \\
\hline 4 & Hexane : Acetone $(8: 2)$ & 0.43 & 0.43 \\
\hline 5 & Acetone : Benzene $(7: 3)$ & 0.43 & 0.47 \\
\hline 6 & Acetone : Benzene $(6: 4)$ & 0.41 & 0.41 \\
\hline
\end{tabular}

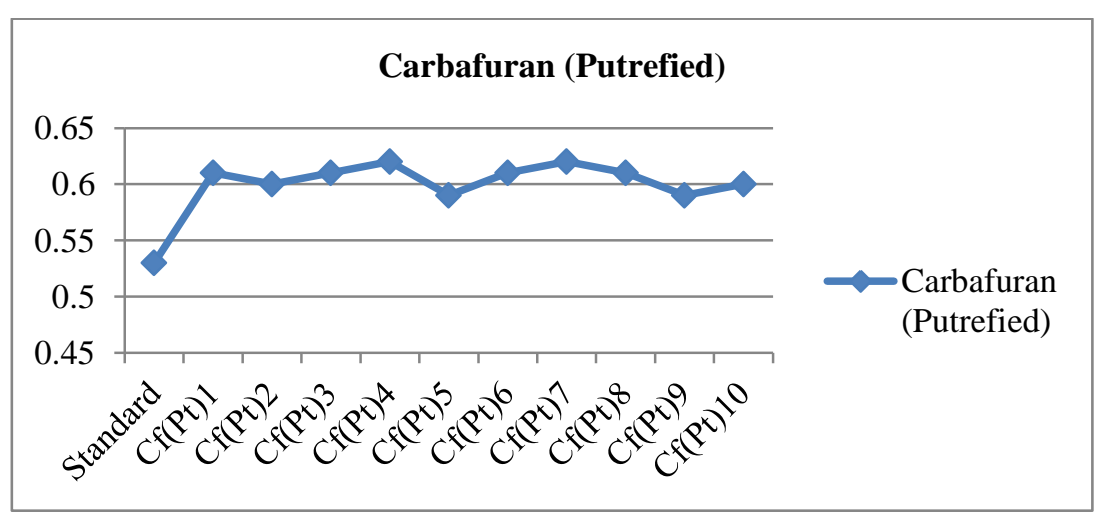

Graph 1: Showing Rf Values of carbafuran (putrefied) 


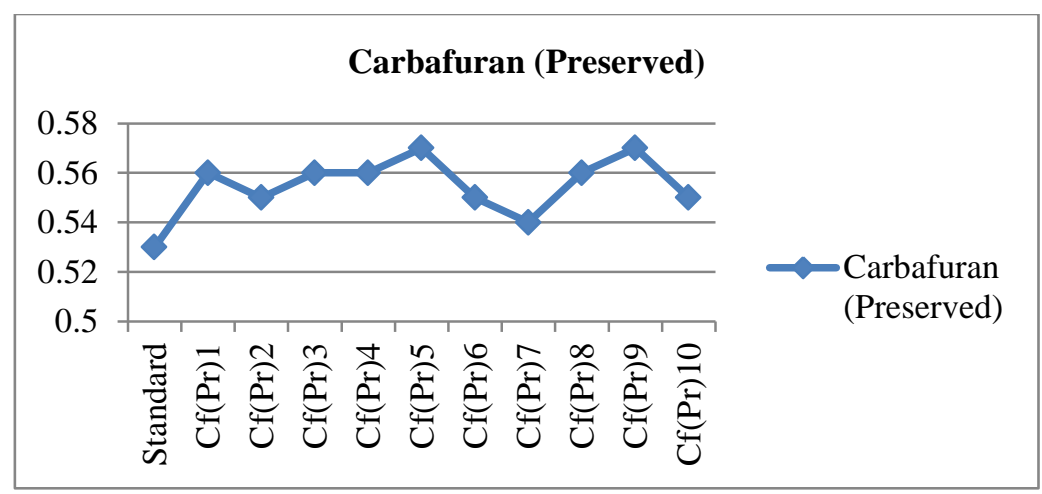

Graph 2: Showing Rf Values Of Carbafuran (Preserved)

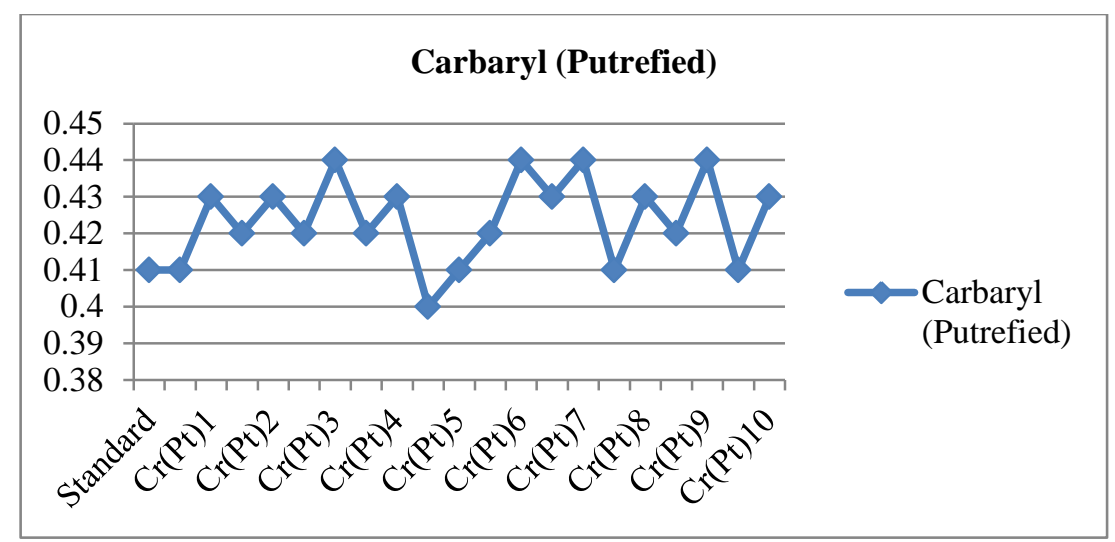

Graph 3: Showing Rf Values Of Carbaryl (Putrefied)

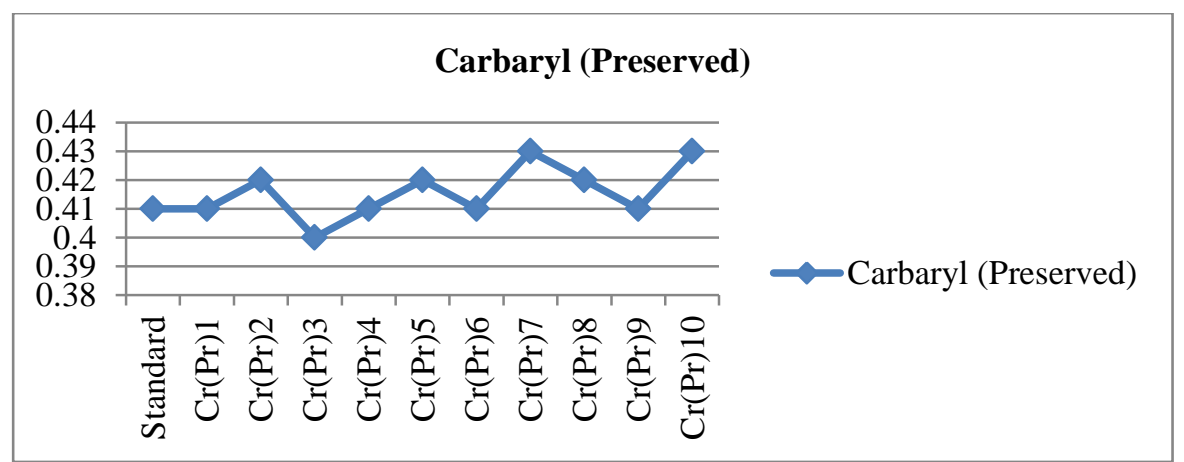

\section{Graph 4: Showing Rf Values Of Carbaryl (Preserved)}

\section{Conclusion}

The effects of temperature and/or daylight on sample condition and analyses are very significant as the analyte of interest present in the Biological matrix may be degraded by the activity of various metabolizing enzymes over a period of time. This subject needs further study for longer time durations so as to understand the performance of putrefied and preserved samples better, as their analytical profiles show differences. The study needs to be replicated on other classes of insecticides as well that are commonly encountered in Forensic Investigations.

\section{References}

1. https://en.wikipedia.org/wiki/Carbamate

2. Navinkumar M. Varma, **S.D.Kalele. Study of Profile of Deaths due to Poisoning in Bhavnagar Region. J Indian Acad Forensic Med. October- December 2011;33.

3. Surendra Khosya ${ }^{1 *}$ and SR Meena. Current Trends of Poisoning: An Experience at a Tertiary Care Hospital Hadoti Region, Rajasthan, India. Journal of Clinical Toxicology. Khosya and Meena, J Clinic Toxicol 2016;6:2. 